\title{
APPLICATION OF \\ PROJECT/PROBLEM-BASED LEARNING IN MICROELECTRONICS
}

\author{
Said Al-Sarawi \\ The Centre for High Performance Integrated Technologies and Systems (CHiPTec), \\ School of Electrical and Electronic Engineering, The University of Adelaide, North Ter- \\ race, Adelaide SA5005, Australia \\ Said.AlSarawi@adelaide.edu.au
}

Abstract: This paper presents an application of problem/project based learning (PBL) to a new course called Analog Microelectronics in the School of Electrical and Electronic Engineering at The University of Adelaide. The course is part of the fourth year programs for B.E. (Computer Systems Engineering) and B.E. (Electrical and Electronic Engineering). The paper highlights the motivation behind the proposed introduction of the new approach and the benefits of moving to a PBL teaching style in contrast to traditional lecturing style. Also this paper presents a sample problem definition that was used in the course. The outcome of the new teaching style was evaluated through exam performance and formal feedback proceeders.

Keywords: Project-based learning, PBL, problem-based learning, teaching engineering

\section{INTRODUCTION}

Problem-based learning and project-based learning are two teaching styles that commonly used in teaching. Before diving into the differences and similarities of the two approaches, the definitions of the two basic words Problem and Project will be considered first. In the Macquarie English dictionary [5] there are a number of definitions for the word 'problem.' Two of these definitions are: 1 . any question or matter involving doubt, uncertainty or difficulty, 2. a question proposed for solution or discussion. In some cases the word can be used as adjective to mean: difficult to train or guide; unruly. While the word 'project' is defined as something that is contemplated, devised, or planned; a plan; a scheme; an undertaking. The verb form of the word project can 
have one of the following meanings: 1 . to propose, contemplate, or plan. 2. to throw, cast, or impel forward or onwards. 3. to set forth; present. 4. to throw or cause to fall upon a surface or into space; as a ray of light, a shadow, etc. 5. to cause (a figure or image) to appear as on a background. 6. to visualise and regard (an idea, etc.) by straight lines rays (parallel or from a centre) which passes through all points of it and reproduce it on a surface or other figure.

By comparing the meaning of 'project' and 'problem' words it is evident that they have a complementary meaning and they are both used to provide instructional and teaching strategies.

The difference between project-BL and problem-BL seems in some cases vague. For example, it is discussed in the literature [13] that there is very little difference between the two strategies. However, a discussion on IMSACPBL-ListServ regarding the differences between project-BL and problem-BL created much of discussion identifying that project-BL has defined specifications that are given and an end product is always in mind. Such production requires specific knowledge or skills and typically raises one or more problems that need to be solved by the students. The common sequence for project-BL is that students 1 . define the purpose for creating their end product, 2. research the topic, 3. create a plan, 4. resolve issues and problems related to production, 5 . finish their product. In contrast, the sequence in problem-BL is that 1 . students are presented with a problem, 2 . organise any previous knowledge related to the problem, 3 . identify sources of information, 4 . devise a plan for information gathering, 5. perform the research, 6. present their conclusions and may or may not have an end product [9].

From the above discussion, the similarity between the Project-Based Learning (project-BL) and problem-Based Learning (problem-BL) is that they both try to mimic the professional situations in either giving a problem or a project with more than one way to either solve the problem or implement the project [9]. Furthermore, both strategies are group oriented that seek out multiple sources of information and involve a lecturer as a facilitator or coach. Also the assessment for both strategies is based on an authentic approach to educational assessment [11].

In summary, the choice between problem-BL and project-BL depends on the discipline [21]. In case of engineering, project-BL is best suited for this decipline and can deliver the required instructional values. Hence, a project-BL was adopted for the development of the new Analog Microelectronics course. Furthermore, if the emphasis in problem-BL is extended to include the process of getting to the solution, it can be argued 
that project-BL is a superset of problem-BL and hence the $\mathrm{PBL}$ acronym can be used interchangeable to imply either project-BL or problem-BL.

This paper presents an application of project-BL to a new course called Analog Microelectronics in the School of Electrical and Electronic Engineering of The University of Adelaide. The course is part of the fourth year plan for the Bachelor of Engineering degree for both Computer Systems Engineering (CSE) and Electrical and Electronic Engineering (EEE). The paper discusses the motivation behind the introduction of the new approach and the benefits of moving to a PBL teaching style in contrast to traditional teaching style. Also the paper presents a sample problem that was used in the course. The outcome of the new teaching style was evaluated formally through exam performance and Student Experience of Learning and Teaching (SELT), which is a course questionnaire that is prepared by the Centre for Learning and Professional Development (CLPD) at the University.

The new course aims at providing students with theoretical background, analysis and design skills needed to design analog integrated circuits using CMOS technology, starting from common system specification for analog systems down to physical implementation of these systems. The course was designed as a combination of two parts [15]. The first presented a number of lectures on specific topics, while the second part is composed of three design projects. Two of these projects were designed to present the concept of project based learning (worth $10 \%$ of the total assessment) in addition to preparing the students for the major project (worth $30 \%$ of the total assessment). The major project was selected and prepared to fully utilise the PBL style.

Section 2 presents the motivations behind the introduction of PBL to the new course. Section 3 presents a literature review of the problemBL and project-BL. Section 4 presents the development of the course. Section 5 presents a sample problem definition that was used in the course. Section 6 presents an overall discussion and evaluation of the implemented teaching style.

\section{MOTIVATIONS}

In a press release by the Institute of Electrical Engineers (IEE) in the United Kingdom, problem-based learning was proposed as a new method of learning that aims at improving the skills and employability of electronics graduates at three UK universities. These universities are University College London (UCL), University of Manchester Institute of Science and Technology (UMIST) and the University of Bristol. It was proposed that from 2004, Master of Engineering and Bachelor of Engi- 
neering in electrical and electronic engineering degrees at the aforementioned universities will incorporate PBL [12]. In addition to other initiative that do encourage incorporating PBL in engineering such as [19], [10], [1],[2],[16]. The later was the first motivation to use problem/projectBL learning in teaching the new Analog Microelectronics course. The second motivation is related to a moderate exposure of the author to problem-based and project-based learning as part of his undergraduate program that he found very useful and stimulating. PBL did benefit the author, and encouraging him to pursue further studies in the area of microelectronics. Furthermore, new teaching sytles such as PBL is encouraged at the University of Adelaide as it is inline with the University Learning and Teaching Plan 2000-2002 [25] in that it:

- ensures strong emphasis on reasoning, thinking and knowledge;

- enhances those aspects of curriculum design and staff development;

- ensures relevant assessment of learning goals and learning;

- provides students with flexible learning and teaching methodologies;

- provides students with good communication and learning skills.

Hence, the motivation in applying this new learning and teaching method to the new course is inline with the University goals for a student centred learning.

\section{LITERATURE REVIEW OF PROBLEM/PROJECT-BL}

Problem/Project-BL is a fairly new teaching and learning approach that was first introduced in the Medical School of McMaster University, Canada, in the late 1960s as a major teaching and learning approach. This approach has extended to many educational institutions around the world. By 1989 it was found that more than $6 \%$ of the medical schools in the United States had either totally PBL curricula or separate PBL tracks. In addition, more than $75 \%$ of these schools claimed to have a form of PBL in their programs [24]. Nowadays, we can see an increasing number of academic institutions have adopted a PBL teaching and learning approach as part of their curricula. This is evident from the amount of literature and research on the problem/project based learning $[7,26],[23],[18],[3]$.

In introducing PBL, to a new course, a number of issues need to be addressed. Some of these issues are as follows. 


\section{Concept Construction}

Problem-based learning is a post-modern approach to tertiary education as it requires the acceptance of post-modern concepts of knowledge, learning and assessment. The knowledge in the new age we live in has evolved dramatically and the basic set of knowledge that defines the set of relevant known knowledge has also changed in character. Hence, the learning approach to acquire this knowledge should also evolve. While the traditional method of gaining knowledge can be used to acquire the evolving knowledge, it can be argued that PBL presents a good approach to acquire knowledge by concentrating on the process of solving a problem rather on the solution itself. Hence, the traditional form of assessment might not be possible. The PBL approach was proposed to realign education to increase its relevance to the perceived needs of the community. And that is the reason behind its acceptance in professional education. "This general acceptance includes the student, the teacher, the faculty, accreditors, profession in general, and the wider community and has been referred to as a general framework of mutual understanding and as a network of comprehension" [4].

\section{Assessment}

The use of PBL encourages the stimulation of the student's way of thinking by encouraging him/her to find a path(s) leading to a solution(s). It is acceptable in PBL that multiple paths may exist to single or multiple solutions. The student path(s) to the solution(s) can be used in assessing the student's learning and gained knowledge. One issue that should be taken care of in assessing PBL is the subjective nature of the assessment. Such nature is usually faced with considerable suspicion by education community, as quality assurance might not be guaranteed [4]. Nevertheless, the subjective assessment seems to achieve the desired outcome from $\mathrm{PBL}$, as it is evident from the large number of professional institutions that use PBL and commended it as an effective teaching and learning approach.

\section{Managing Students}

Managing students is one of the issues that needs to be addressed when constructing a PBL based course. A number of issues can arise as a result of students working in groups. Some of the issues that the author came across in managing students are: (a) time management within a group, (b) participation and interaction in a group, (c) motivation, (d) dedication, (e) personal communication, (f) cultural differences. In 
most cases, these issues were resolved within the group and resulted in a good outcome. Similar issues were reported in PBL based courses, as demonstrated by the case studies reporters in [22], [6] and [14].

\section{Evaluation}

Evaluating PBL at the end of each semester is very important to provide the required feedback to the current students and fine tune PBL for future years. Two types of evaluations were used. These are the students' and the lecturer's evaluation of the PBL based course. Such evaluations are becoming more necessary for the purpose of accountability and quality assurance in education. The evaluation of the course was gathered through interactions between the students and lecturer and formal evaluation of the course and the lecturer.

The procedures followed in this section are based on a PBL developers' website [2], that the author did find very useful and systematic in preparing a PBL based course.

\section{DEVELOPING A PBL FOR ANALOG MICROELECTRONICS COURSE}

Analog Microelectronics is a new fourth year elective course for B.E. (Computer Systems Engineering) and B.E. (Electrical and Electronic Engineering). The number of students enrolled in this course last year was 16 students, which is a good manageable number of students to try PBL. From previous teaching experience, managing a large number of groups can be simplified by getting the students to select or form their own group. This usually resulted in the least number of problems within a group so far. In addition to providing the students with all the relevant information online, access to online discussion forums and accessible consulting hours during the semester. The later resulted in manageable groups with the least number of problems. As the course covers a number of topics, it was found it is difficult to set-up a PBL assignment for each topic. Hence, the course was delivered as a combination of traditional lecture and PBL styles. For the given problems, the students were given introductory lectures that did range between 10-30 mins covering the requirements for the problem and allowing students to ask questions related to the problem. The procedures followed in developing these problems are based on the PBL developers' website [2], that the author found useful and systematic in preparing a PBL based course. Each step is addressed in a separate subsection. 


\section{How to design PBL assessments?}

In contrast to the traditional method of assessment, PBL assessment methods are much better at evaluating knowledge that students gain during the course. A number of assessment types can be used as part of PBL assessments: such as reflective problem log, self-assessment, peer assessment, presentation and demonstration, reflective essays, role-play, etc. Of these assessment types the self assessments coupled with journal writing, presentation and demonstration is believed to yield the best outcome for the current course. In case of the self assessment, group members had to decide between themselves on how much each of them did contribute towards the final outcome of the project [2]. It is proposed that in the next delivery of the course, the student should provide peer assessment on how much each member did contribute to the final outcome of the course. This mark is then used to adjust a percentage of the total work. To enable the students to provide feedback to the lecturer on their learning and the knowledge they gained from the course, a demonstration/presentation of their design strategy, final outcome, and problems faced, approach to solving these problems was organised.

\section{How to support the coaches?}

As this is a specialised course, the chosen coaches are familiar with the analog microelectronics and currently conducting research in this area. This was done by utilising some of the author's postgraduate students. In addition, coaches were addressed by the course coordinator about the given project and common problems the students might face during their project. The coaches sheet of the problem was accompanied with a description of the problem, possible solutions and the relation of the problem to the course outcome, a list of preferred resources and webpage links were also be provided.

\section{How much content should be covered?}

The amount of course content that should be covered, when using PBL teaching style, is hard to decide upon and that did depend on the problem given to the students. To ensure that the students have the basic knowledge in advance before they were given the problem. The needed topics are covered during lecture time slots and the pedagogy behind the problem in question was explained. This short lecture did range between 10 to 30 mins. Then the students were given the project at the end of the lecture and invited to ask questions about the project next lecture. 


\section{How does PBL develop generic skills?}

The problems that the students were exposed to are believed to develop learning experiences, self-confidence in skills, abilities and knowledge [8] - as these problems do closely mimic common design problems that electronic engineers face in real life situations. The generic skills that the students did gain from this course are problem solving and critical thinking [20]. Both skills are needed to decide on which design approach to use and the implication of the group decisions on the time it takes to finish a design. The development of personal communication is also another skill that student developed as part the project [15]. Such skills are very important in the workforce as most electronic systems are a team effort and require the collaboration of a huge number of group members.

\section{How long does it take to develop a PBL course?}

PBL can be looked at as a closed loop control system, in that the lecturer has to go through a number of iterations to get the best outcome from the system. However, there are a number of criteria that should bound the given problem. Without defining these criteria the whole exercise can be catastrophic as is the case with a control system without defined stability criteria. Hence it is very important to get as close as possible to the desired outcome from initial step or conditions. As a result, extra effort and time was dedicated to ensure a correct start to the PBL teaching style. It is expected that less effort would be needed in setting up and maintain the course in the next delivery.

\section{Supporting resources}

A number of resources were provided to the students during the course. The first source of resources is the course textbook, recommended reference material and tutors. These reference materials are books and technical articles. Also, the Digital Resources Management Centre in the University was utilised very efficiently to give students online access to materials by using MyUni Online Learning \& Teaching. In addition to providing the students with regular consulting hours and utilising the remaining lecture time for questions and support. 


\section{ANALOG MICROELECTRONICS PBL EXAMPLE: AMPLIFIER DESIGN PROBLEM 1}

- Problem Aims: The aims of this problem are $(i)$ to introduce the concept of simple CMOS amplifier design, (ii) to show the trade-off between gain, bandwidth and power, (iii) and the effect of supply voltage on dynamic range, and $(i v)$ the importance of considering parasitic capacitance when designing analog circuits.

- Problem Statement: A digital CMOS inverter can be thought of as an analog amplifier if it is biased appropriately. Such a configuration is usually referred to as push-pull CMOS inverter/amplifier. Design this amplifier circuit in TSMC $0.25 \mu \mathrm{m}$ CMOS technology using Sue MicroMagic Design tools, then draw the corresponding layouts for it using Magic Layout editor.

\section{- Specifications:}

- at least $50 \mathrm{~dB}$ gain,

- a minimum bandwidth of $1 \mathrm{MHz}$,

- operating from a 2.5 Volt supply voltage, and

- power consumption should be less than $200 \mu \mathrm{W}$.

\section{- Instruction to Tutors}

All the resources available to the students are also available to the coaches in addition to special instruction and comments on how to tackle the design problems. The design flow that the student should follow to have a successful design is shown in Figure 1. This design flow was explained in details to both the students and coaches, separately.

\section{DISCUSSION AND EVALUATION}

The given problems cover $80 \%$ of the course aims. So, the rest can be delivered to the students either as homeworks, tutorials or common teaching style. This matter needs to be investigated further. In general, PBL will be very valuable for the students and will enhance their learning ability and knowledge. For example, as part of the Student Experience of Learning and Teaching (SELT) survey, when the students were asked "what are the best aspects of the lecturer teaching?" Some answered $(i)$ "He introduced Problem-based Learning which was helpful," (ii) "Introduced PBL very useful," and (iii) "Hands on approach, 


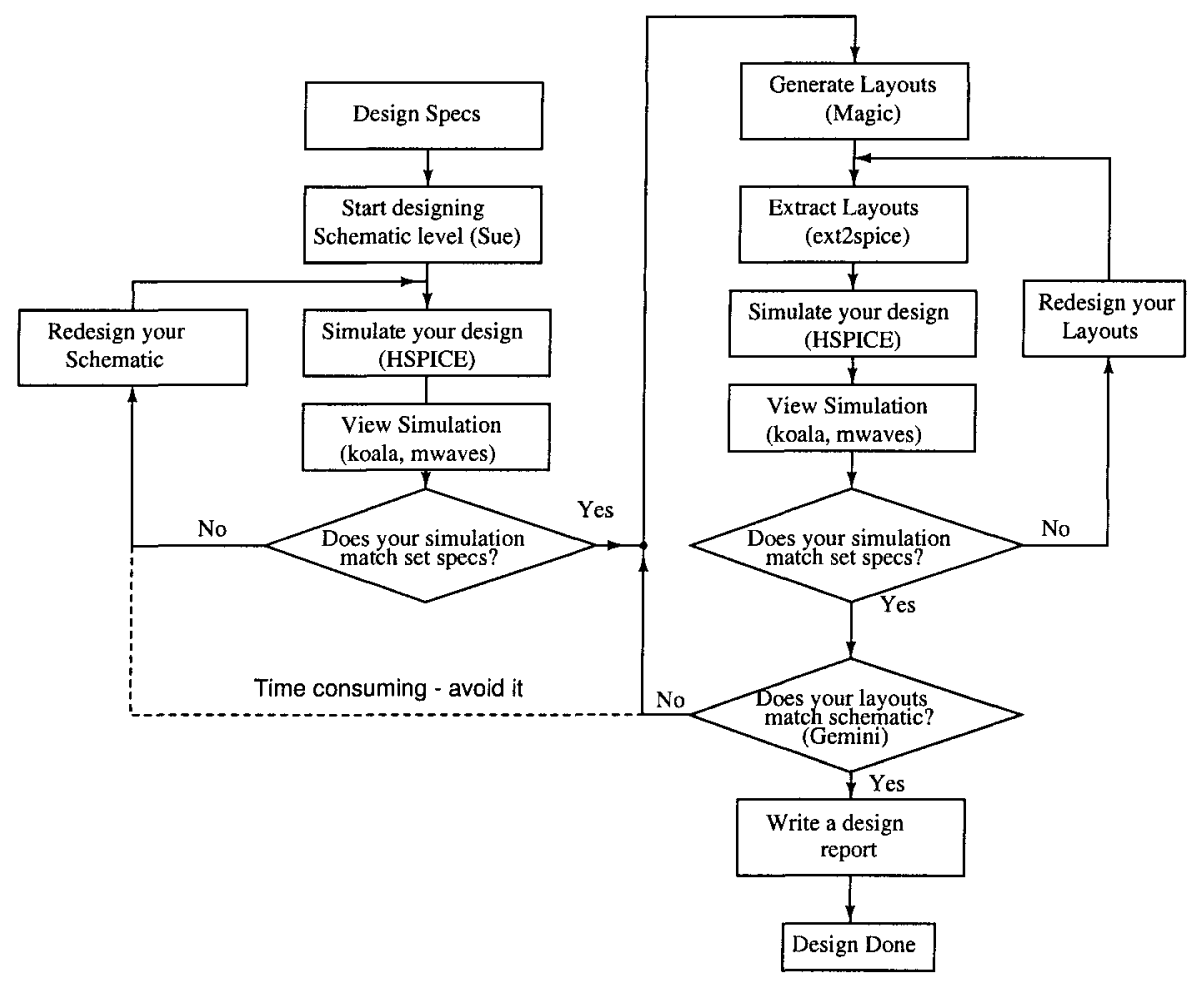

Figure 1. A recommended design flow.

PBL was very useful, not only in practical sense, it helped the final project in the end." Also while other students indicated that the problems were too hard and need to be spread out in time. Considering the fact that the Analog Microelectronics course is a new course and the used approach is new to the students, these comments are acceptable. Furthermore, as PBL challenges students to take more responsibility for their own learning and motivation and encourage them to study at their own pace. Some students did find PBL very useful, while students who are used to following clearly defined instructions and rely on other students see this teaching style as daunting and time consuming [17].

From the lecturer point of view, both the course and lecturer evaluations indicated that PBL teaching style is successful. Also, PBL forces the lecturer to be well prepared and ready for teaching the course, as students learn at their own pace rather than the lecturer's own pace. In the long run, it is expect that the next delivery of the course would be 
easier, as a larger collection of design problems will be and ready for use. Hence less organisation is expected for future delivery.

In the next delivery of the course it is planned to collect further feedback from students using questions such as [17]:

- what do you hope to gain from problem-based learning?

- what major problems have you experienced with problem-based learning?

- now that you have listed what you hope to gain from problembased learning, what kind of lecturer is most helpful to you in achieving your learning goals? Please list the characteristics of a good lecturer in this type of course?

The above questions will allow the lecturer to evaluate $(i)$ the effectiveness of PBL and (ii) the students' expectations from PBL, (iii) the student perception of the role of lecturer in a PBL based course.

\section{ACKNOWLEDGEMENT}

The author would like to acknowledge and thank Dr. John Willison from Centre for Learning and Professional Development for useful discussions and comments regarding. Dr. Gerry Mullins from Adelaide Graduate Centre and Mr. Mike Liebelt, Head of School of Electrical and Electronic Engineering for useful discussions and comments regarding setting up the PBL part of the course.

\section{REFERENCES}

[1] D.R. Brodeur, P.W. Young, and K.B. Blair. Problem-based learning in aerospace engineering education. In Proceedings of American Society for Engineering Education Annual Conference $\mathscr{E}$ Exposition. American Society for Engineering Education, 2002.

[2] Central Queensland University. PBL Portal, 2002. http://pbl.cqu.edu.au/.

[3] S.E. Chen, R. Cowdroy, and M. Kingsland, A. Ostwald, editors. Reflections on Problem Based Learning. Australian P.B.L. Network, 1994.

[4] R.M. Cowdroy. Reflections on Problem based learning, chapter 3, pages 45-56. Australian P.B.L Network, 1994.

[5] A. Delbridge, JRL Bernard, D. Blair, P. Peters, and S. Butler, editors. The Macquarie Dictionary. The Macquarie library Pty Ltd, 2nd edition, 1991.

[6] D. Dolmans, I. Wolfhagen, and C. van der Vlenuten. Problem-Based Learning: Case studies, experience and practice, chapter 18, pages 135-141. Kogan Page, 2001.

[7] D.H.J.M. Dolmans, W. De Grave, I.H.A.P. Wolfhagen, and C.P.M. van der Vleuten. Problem-based learning: future challenges for educational practice and research. Medical Education, 39(7):732-741, 2005. 
[8] G.W Ellis, G.E. Scordilis, and C.M. Cooke. New pedagogical approaches in engineering mechnanics yield increased student understanding, confidence, and commitment. In 33rd ASEE/IEEE Frontiers in Education Conference, pages 15-20, Westminster, Colorado, USA, November 2003.

[9] C. Esch. Project-based and problem-based: The same or different?, 1998. http://pblmm.k12.ca.us/PBLGuide/PBL\&PBL.htm.

[10] Sven K. Esche. Project-based learning (PBL) in a course on mechanisms and machine dynamics. In World Transactions on Engineering and Technology Education, volume 1, pages 201-4, 2002.

[11] P. Hager and J. Butler. Reflections on Problem based learning, chapter 2, pages 35-44. Australian P.B.L Network, 1994.

[12] IEE. Problem-based learning initiative, 14 January 2002. http://www.iee.org/Membership/accreditation/pbl.cfm.

[13] L. Kaisler. Problem-based vs. project-based. The Problem Log, IV(I):3-4, 1999. http://www.imsa.edu/team/cpbl/learning/problemlog.html.

[14] D.M. Kaufman and K.V. Mann. Problem-Based Learning: Case studies, experience and practice, chapter I Don't want to be a Groupie - Ch. 19, pages 142-8. Kogan Page, 2001.

[15] J. E. Mills and D.F. Treagust. Engineering education : is problem-based or project-based learning the answer? Australasian Journal of Engineering Education, (2003-3):2-16, December 2003.

[16] Monash University. PBL, May 2002. http://cleo.eng.monash.edu.au/teaching/pbl-list.

[17] G. Mullins. Reflections on Problem based learning, chapter The Evaluation of Teaching in a Problem-Based Learning Context - Ch.7, pages 105-24. Australian P.B.L Network, 1994.

[18] G. Mullins, J Wetherell, G Townsend, T Winning, and F. Greenwood. ProblemBased Learning in Dentistry: the Adelaide Experience. Dental School, The University of Adelaide, 2001.

[19] A. Pester, E. Ofner, H. Grnbacher, and A. Moore. Problem based learning in microelectronics: Approach, experience, examples. In Entwicklung einer technischen Elite, the University Kharkiv, Kharkiv, Ukranie, May 2002.

[20] Jennifer Ross. A microelectronics curriculum designed with industry input and project-based laboratories. In NSF grantees poster session at 1998 ASEE conference, Seattle WA, USA, 1998.

[21] Maggi Savin-Baden. Problem-based learning in higher education : untold stories, chapter Ch. 1 - Problen-based learning underestimated, pages 13-26. Open University Press, Buckingham, 2000.

[22] C. Schuler and A. Fincham. Problem-Based Learning: Case studies, experience and practice, chapter To Admit or not to Admit? That is the Question - Ch. 17, pages 126-34. Kogan Page, 2001.

[23] P. Schwartz, S. Mennin, and G. Webb, editors. Problem-Based Learning. Kogan Page, 2001.

[24] P. Schwartz, S. Mennin, and G. Webb, editors. Problem-Based Learning: Case studies, experience and practice, chapter Introduction, page 2. Kogan Page, 2001. 
[25] The University of Adelaide. The Adelaide University Learning and Teaching Plan 2000 - 2002, 2003.

[26] B Wallis, editor. Problem Based Learning The Newcastle Workshop. Newey and Beath Printers Pty. Ltd, 1989. 